Inga Mai Groote (Fribourg)

\title{
Zum Gedenken an Renate Groth (1940-2014)
}

Am 11. September 2014 verstarb mit Renate Groth eine engagierte Vermittlerin zwischen Musikwissenschaft und Musiktheorie. Nach dem Studium der Schulmusik mit dem instrumentalen Hauptfach Viola da gamba und den Nebenfächern Anglistik und Philosophie und Tätigkeit im Schuldienst unterrichtete sie an der Hochschule für Musik und Theater Hannover, wo sie ab 1982 eine Professur für Musiktheorie innehatte. 1993 habilitierte sie sich im Fach Musikwissenschaft und wurde 1996 an das Musikwissenschaftliche Seminar der Universität Bonn berufen, wo sie bis 2003 lehrte. Das Interesse für Brückenschläge zwischen Musikwissenschaft und Musiktheorie prägte ihre wissenschaftlichen Arbeiten. Als Mitbegründerin der Zeitschrift Musiktheorie (1986), zu deren Herausgebern sie zehn Jahre zählte, wirkte sie an einem Projekt mit, das unterschiedliche Perspektiven auf Musiktheorie verschränken wollte. Die Rekonstruktion der historischen Konfigurationen des Musikdenkens und die Frage nach dem Spannungsverhältnis von kodifizierter Kompositionslehre und schöpferischer Tätigkeit des Komponisten bildeten Schwerpunkte ihrer Forschungen. Bereits die bei Carl Dahlhaus entstandene Dissertation (Die französische Kompositionslehre des 19. Jahrhunderts) diskutierte die pädagogische Utopie der Lehrbarkeit von Komposition, wie sie sich vor dem institutionellen Hintergrund des Pariser Conservatoire manifestierte; an Autoren wie J. J. Fux oder Antonio Eximeno interessierten sie Fragen der Rationalisierbarkeit und des historischen Stilverständnisses, während das Zusammenspiel dem Kontext der italienischen Akademien bei Padre Martini in den Blick trat. Für die Beschäftigung mit der italienischen Theorie des 17. Jahrhunderts und deren Pragmatismus kann besonders ihr gewichtiger Beitrag zur Geschichte der Musiktheorie stehen.

Musikgeschichte dachte sie in länderübergreifenden Dimensionen, wobei ihre eigenen Forschungsschwerpunkte Italien und Frankreich charakteristische thematische Akzente setzten. Gerade am Beispiel Frankreichs warb sie für die kritische Reflexion von historiographischen Vorstellungen, um etwa im Umfeld von Vincent d'Indy das Verhältnis von Geschichte und kreativer Erneuerung zu thematisieren. In vielfältiger Form engagierte sie sich für den Gedankenaustausch, auch interdisziplinär und international, so als Mitglied der Kommission Auslandsstudien der GfM und Beiratsmitglied der Gesellschaft für Musiktheorie; sie vertrat die Musikwissenschaft im Bonner Graduiertenkolleg „Die italienische Renaissance und ihre europäische Rezeption“. Vor allem aber war sie von 1999 bis 2013 Vorstandsmitglied des Vereins Beethoven-Haus, wo sie durch den Aufbau des wissenschaftlichen Beirats, dem sie acht Jahre vorstand, die wissenschaftliche Arbeit des Beethoven-Archivs unterstützte. Als Lehrende leitete sie zum selbständigen Arbeiten und kritischen Denken an, sie legte auch hier Wert darauf, ein Bewusstsein für die „Gemachtheit" von Historiographien zu wecken und nach der kulturgeschichtlichen und ideellen Einbindung von Musikgeschichte zu fragen. Studierende, Kollegen und Freunde werden sie als vielseitig interessierte Wissenschaftlerin und intellektuell anregende und humorvolle Gesprächspartnerin in Erinnerung behalten. 